This item was submitted to Loughborough's Institutional Repository (https://dspace.lboro.ac.uk/) by the author and is made available under the following Creative Commons Licence conditions.

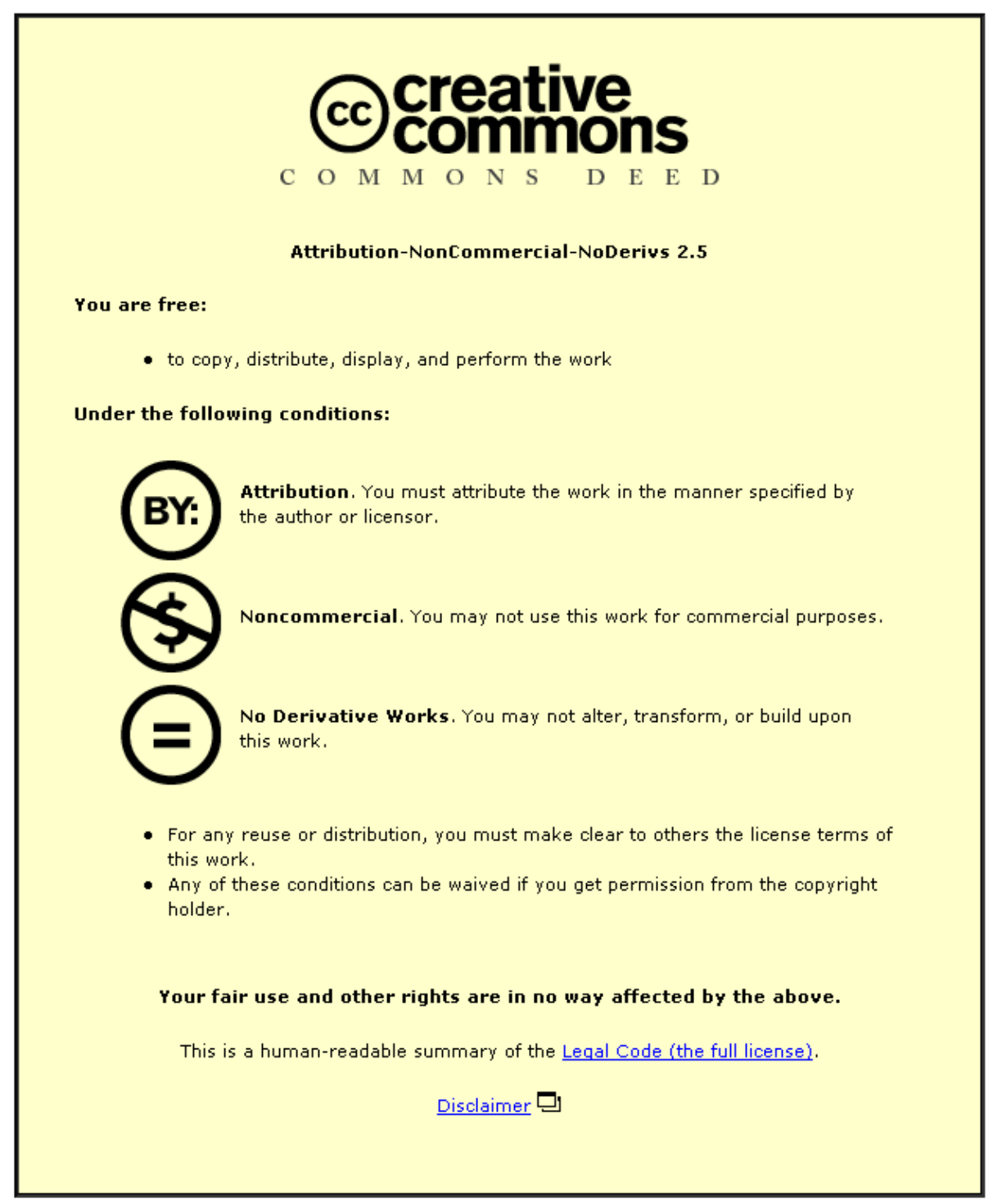

For the full text of this licence, please go to: http://creativecommons.org/licenses/by-nc-nd/2.5/ 


Proceedings of the Institution of
Civil Engineers
Geotechnical Engineering 161
October 2008 Issue GE5
Pages 247-257
doi: 10.1680/geng.2008.161.5.247
Paper 70005।
Received 05/I 0/2007
Accepted I8/07/2008
Keywords: design methods \& aids/
geotechnical engineering/piles \&
piling

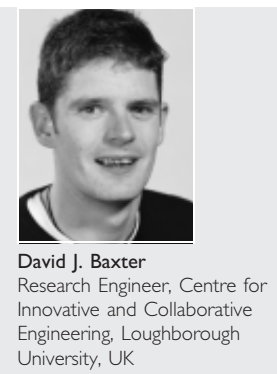

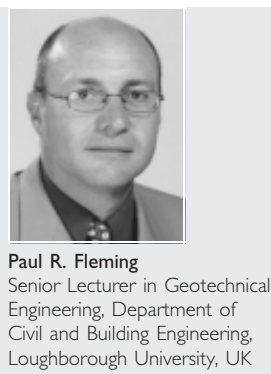

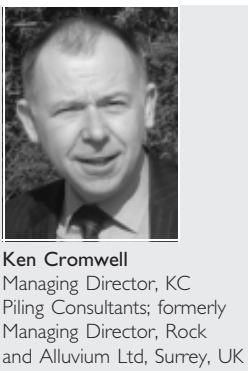

\title{
Refining shear strength characteristic value using experience
}

D. J. Baxter MEng, MSc, CEng, MICE, N. Dixon BSc, PhD, FGS, P. R. Fleming BEng, PhD, MIHT and K. Cromwell BEng, CEng, MICE

\begin{abstract}
Determination of characteristic values for soil properties forms a critical step in the foundation design process. The refinement of such values to account not only for site-specific data but also for existing knowledge and previous experience can result in more efficient design and increased confidence. This paper presents a logical, pragmatic approach for the selection of characteristic values of shear strength for the design of piled foundations within the context of Eurocode 7. The process of refining conceptual models of geotechnical properties in a quantitative, objective manner to include previous knowledge and wider experience is described and demonstrated through case study examples. The result of applying the updating methods is to achieve a revised mean that is a weighted average of the site data and the prior knowledge; the weighting is a function of the variability of each set of data. Such refinement relies upon a quantification of previous knowledge: mean values, trends, variations and distributions of data are required, and in this paper a dataset for undrained shear strength of London Clay is presented and applied to case study examples.

Application of the techniques described leads to a better estimate of the ground properties and a reduction in the risk attached to a design solution.
\end{abstract}

\section{NOTATION}

a

$b$

$c$ estimated minimum value estimated most likely value estimated maximum value undrained shear strength depth below ground level number of data points correlation coefficient coefficient of variation of the derived values characteristic value statistical mean of the derived values mean of the sample data factor relating pile adhesion to soil cohesion mean of the prior data mean of the updated (posterior) data standard deviation of the sample data standard deviation of the prior data standard deviation of the updated (posterior) data

\section{INTRODUCTION}

In geotechnical design, the skill of the engineer lies in determining the ground conditions at a site and how these are best modelled for use in suitable design calculations. It is not surprising, therefore, that a large proportion of the design process is related to the site investigation, its design, execution and interpretation. In this paper, this process is considered within the framework of Eurocode $7 .^{1}$ The design procedure for Eurocode 7 has been described by Simpson and Driscoll, ${ }^{2}$ and is summarised in Fig. 1.

Experience and previously existing knowledge of the ground conditions can be incorporated into the geotechnical model, a process that is often carried out in a subjective manner. In this paper, a quantitative approach to the inclusion of previous knowledge is discussed and applied to examples of bored pile design. To facilitate this, a set of shear strength data from numerous sites has been collated and described. For design purposes, a characterisation of the ground conditions is needed that takes account of variation and the likely deviation that might be expected in the site investigation results. In this paper, a simple statistical approximation is applied to produce a suitable model based on characteristic values of the shear strength at the site. The methods described are then applied to case study examples to demonstrate the influence on design and costs.

\section{BACKGROUND}

\section{I. Modelling ground properties}

For geotechnical design, it is necessary to construct a model of the ground properties that exist at a site. The usual starting point for this is test results from site investigation. These cannot be used for design calculations in their raw form, because account must be taken of variability across the site, the nature of the tests, and the manner in which the structure will interact with the soil. The process of determining values for use in design from site investigation measurements follows an essentially linear progression, throughout which the designer will make and apply numerous decisions and judgements.

This process for determination of ground properties (following Eurocode 7, Part 1) ${ }^{1}$ has been described by $0 \mathrm{rr}^{3}$ and by Frank et al. ${ }^{4}$ Fig. 2 shows the individual steps necessary to establish 


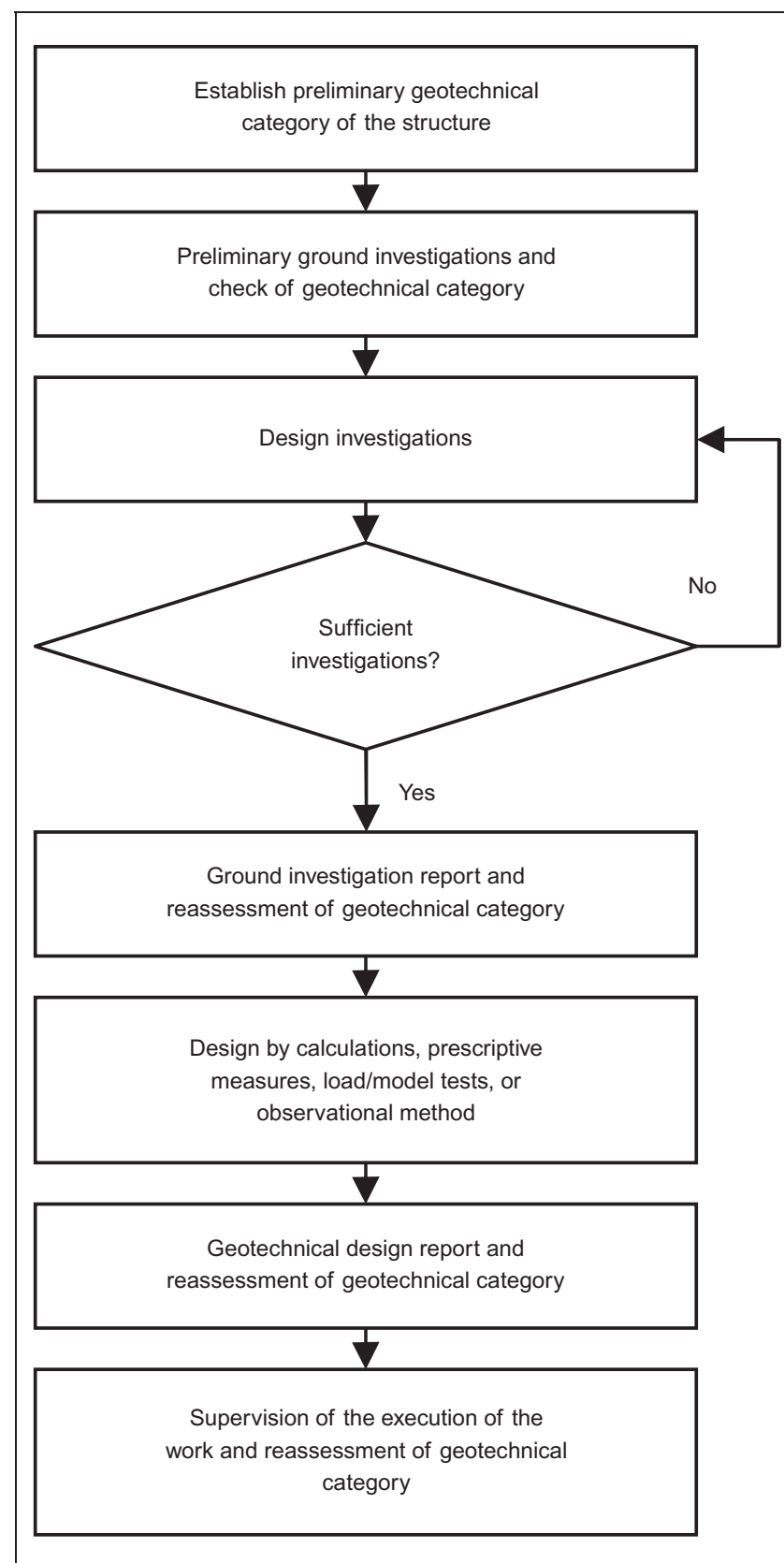

Fig. I. The design process of Eurocode 7 (after Simpson and Driscoll ${ }^{2}$ )

ground properties that can be used in design. The steps are described below and follow the development of soil property values through four stages

- measured values

- derived values

- characteristic values

- design values.

Frank et al. ${ }^{4}$ introduced intermediate steps, most notably the geotechnical parameter value, which allows for consideration of existing knowledge and experience. Ground properties are established primarily from site investigation through tests carried out in situ and on samples (disturbed or undisturbed) taken for laboratory testing. These are referred to as the measured values, and represent the test results (following the application of any test-related corrections, which are independent of further analysis). Where test results do not return a value that can be used directly in design, these need to be converted to derived values by applying theory, empiricism or correlations. An example of this is the correlation of SPT blow counts with undrained shear strength through the relationship proposed by Stroud and Butler. ${ }^{5}$ The geotechnical parameter value is an intermediate stage that allows for an assessment of the influence of the test, with associated corrections, such as a conversion from axisymmetric to planestrain conditions to better represent the design situation. This is also the point at which refinements can be made based upon published data and general experience or prior knowledge.

The derived values (and geotechnical parameter values) are representative only of the sample, and not of the overall distribution of values on the site. The values that describe the properties of the ground at the site, its associated variation, the nature and behaviour of the soil mass and its interaction with the structure are the characteristic values. This characterisation of the site and the geotechnical problem is a vital step in the design and is where the engineer's skill and judgement are applied. The characteristic values are subsequently developed into design values by the application of safety factors.

\subsection{Inclusion of previous experience and prior knowledge}

If information is not sufficient for design, the result is a lack of confidence in the derived values that leads to greater conservatism being called for when obtaining characteristic values. Larger factors of safety would need to be applied. Eurocode $7^{1}$ stipulates that, where statistical methods are employed, the characteristic value should be selected such that the calculated probability of a worse value governing the occurrence of the limit state considered should not be greater than 5\%: the factors of safety have been developed accordingly, and this acts as a motivating factor for increasing the quality of site investigation. Selection of other parameters may also be affected by a low confidence level (even though this can disguise the overall allowance for uncertainty). An example of this can be found in pile design, where the shaft capacity of a pile is related to the soil strength and pile geometry through the adhesion factor $\alpha$. Guidance for pile design in London Clay ${ }^{6}$ indicates that a lower (more cautious) value for $\alpha$ should be used where a site investigation does not meet minimum standards. This restriction is intended to create an incentive to carry out quality site investigation. It does, however, make it difficult to ascertain the degree of confidence assigned to a design. Such an approach is not compatible with Eurocode 7, which deals with the uncertainty solely in the characterisation process, with subsequent application of suitable factors of safety dependent on the confidence in the calculations.

Where previous experience, published data, or knowledge from nearby similar sites exists, a method of combining this information with the site-specific data is advantageous in developing characteristic values. Traditionally, this may have been achieved by application of subjective judgement based on experience. An objective approach is suggested by authors such as Lumb ${ }^{7}$ and Tang, ${ }^{8}$ who have presented methods for the application of statistics, in particular Bayes' theorem, to geotechnical applications. A better estimate of the likely value of the geotechnical parameter values (posterior distribution) can be found by combining information relating to the previous 


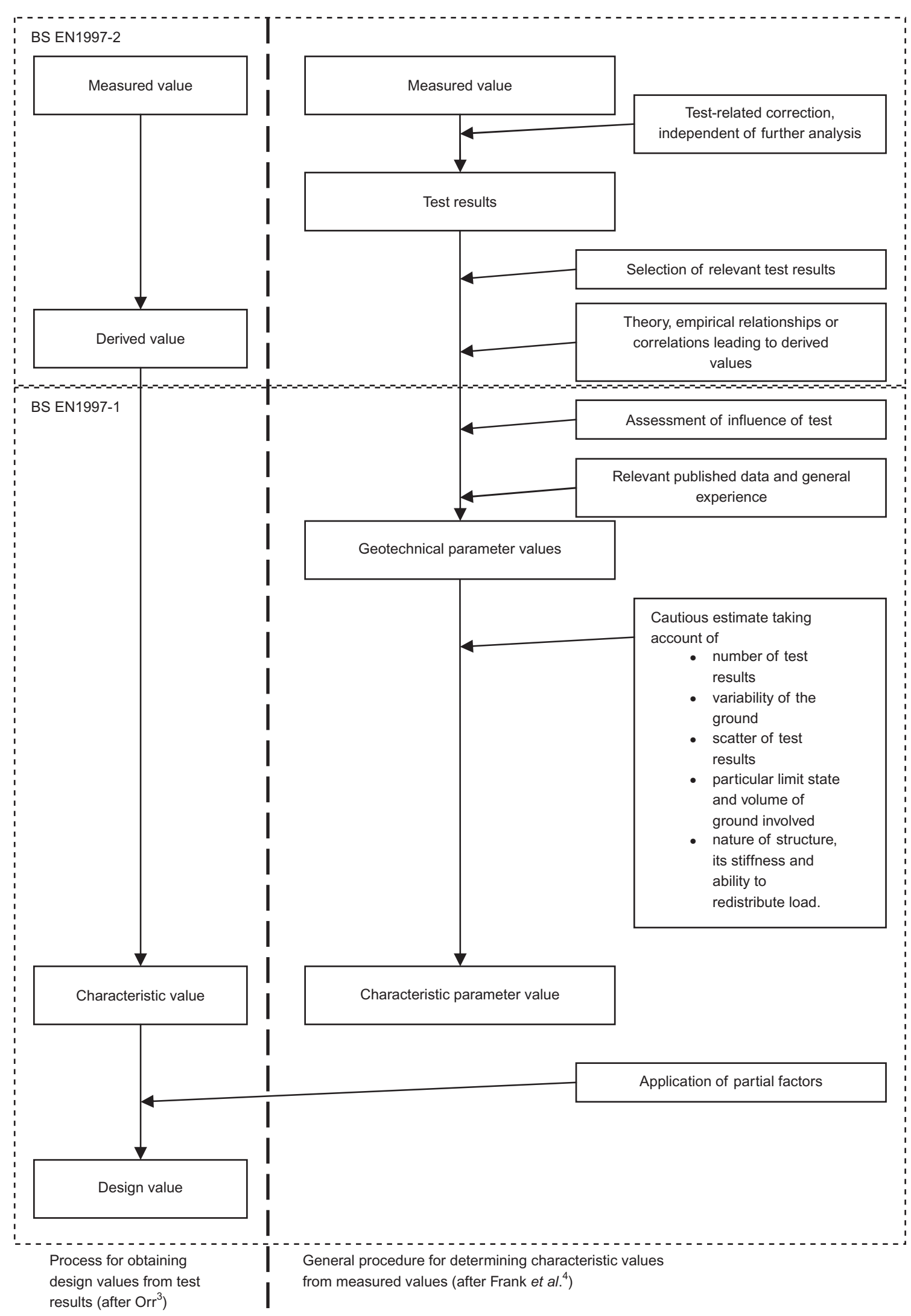

Fig. 2. Steps in determining characteristic and design values (after Orr ${ }^{3}$ and Frank et al. ${ }^{4}$ )

knowledge (prior distribution) and site-specific information. Tang $^{8}$ observed that the posterior distribution is a product of its prior distribution, which represents the data gathered before the additional test data, and the likelihood function, which represents the information based on the additional test data.
This method requires, as a minimum, that summary statistics such as the mean and standard deviation of the previous knowledge are known or can be determined in some way.

If a population is normally distributed, it can be shown by 
application of Bayes' theorem that the posterior distribution is normal, with the mean value and standard deviation calculated using

I $\quad$ Posterior mean, $\mu^{\prime \prime}=\frac{\mu^{\prime}\left(\sigma^{2} / n\right)+\bar{x}\left(\sigma^{\prime}\right)^{2}}{\left(\sigma^{2} / n\right)+\left(\sigma^{\prime}\right)^{2}}$

\begin{tabular}{|} 
Posterior standard deviation, \\
$\sigma^{\prime \prime}=\sqrt{\frac{\left(\sigma^{2} / n\right)\left(\sigma^{\prime}\right)^{2}}{\left(\sigma^{2} / n\right)+\left(\sigma^{\prime}\right)^{2}}}$ \\
\hline
\end{tabular}

where the prior data have mean $\mu^{\prime}$ and standard deviation $\sigma^{\prime}$, and the derived values for the site are represented by the mean $\bar{x}$ and standard deviation $\sigma ; n$ represents the number of data points.

The resulting posterior distribution has a mean that is a weighted average of the prior and sample data means, the weighting being proportional to the variances. The posterior standard deviation will be lower than that for both the prior and sample data distributions as they combine to produce a sharper, more peaked distribution: that is, data points are more closely grouped about the mean.

\subsection{Determination of characteristic value}

The characteristic value is defined in Eurocode 7, Part $1,{ }^{1}$ as a cautious estimate of the value affecting the occurrence of the limit state. The characteristic value must take account of the inherent variability of the soil, measurement errors and the extent of the zone governing behaviour; ${ }^{9}$ further factors leading to differences between derived values and those governing behaviour are listed by Frank et al. ${ }^{10}$ These include, but are not limited to, the presence of soil structure (e.g. fissures), time effects, water softening and the influence of construction activities on the soil.

The characteristic value, used in Eurocode $7,{ }^{1}$ is comparable to the 'conservatively chosen' mean that is traditionally used in the British Standard approach to foundation design. ${ }^{11}$ The degree of conservatism has conventionally been based on local experience or subjective information. For Eurocode $7^{1}$ an objective measure of the degree of conservatism is required to obtain a specific level of safety. One way in which this can be achieved is through the use of statistical methods.

An array of statistical techniques is available and has been presented by Van Alboom and Menge, ${ }^{12}$ who concluded that statistics are a useful tool but that care should be taken regarding the adoption of assumed distributions of the population; care should also be taken that sample sizes are sufficiently large. The introduction of statistical techniques can add unnecessary complication to the design process, and demands additional skills from the engineer. This can be overcome by using an easily employed approximation for the statistical definition of the characteristic value, such as that proposed by Schneider ${ }^{13}$ and described by

$$
X_{\mathrm{k}}=X_{\mathrm{m}}\left(1-\frac{V_{x}}{2}\right)
$$

where $X_{\mathrm{k}}$ is the characteristic value, $X_{\mathrm{m}}$ is the statistical mean of the derived values, and $V_{x}$ is the coefficient of variation of the derived values. $X_{\mathrm{m}}$ and $V_{x}$ can be estimated from the sample distribution when there are sufficient data to provide an approximation of the population. D'Agostino and Stephens ${ }^{14}$ suggest that at least 150 points would be required for a dataset to be representative of the population. Where there are insufficient data, $X_{\mathrm{m}}$ can be determined using the approximation

\begin{tabular}{|l|l|}
\hline 4 & $X_{\mathrm{m}} \approx \frac{a+4 b+c}{6}$ \\
\hline
\end{tabular}

where $a$ and $c$ are the estimated minimum and maximum values, and $b$ is the estimated most likely value. Estimations can be based on experience, judgement and published data. Schneider ${ }^{13}$ found the coefficient of variation $V_{x}$ of the undrained shear strength of a soil to be in the range $0 \cdot 3-0 \cdot 5$, and recommended a value of $0 \cdot 4$. Many other authors have found similar results: Hooper and Butler ${ }^{15}$ found a coefficient of variation of $0 \cdot 25-0 \cdot 33$ for triaxial tests carried out on $100 \mathrm{~mm}$ diameter samples of London Clay from a single site. Phoon and Kulhawy ${ }^{16}$ report a range for $V_{x}$ of undrained shear strength of fine-grained soils of $0 \cdot 06-0 \cdot 56$, with a mean value of 0.33 based on 38 separate datasets. Lumb ${ }^{7}$ observed a range for the coefficient of variation for shear strength of Hong Kong Marine Clay of $0 \cdot 2-0 \cdot 5$.

Schneider ${ }^{13}$ demonstrated that approximations of characteristic value using equation (3) were consistent with the values estimated by engineers, and it has been in use in Switzerland for many years. A sufficiently accurate solution can be obtained without extensive calculations, and this simplicity, coupled with the flexibility to include an element of engineering judgement, makes it a useful tool for practising engineers.

\subsection{London Clay}

London Clay has been chosen as the subject for this study. There are two reasons behind its selection. London Clay covers a large geographical area, which has a long and welldocumented history of construction development. There is therefore an existing associated body of knowledge upon which the current research can build and extend. This history of construction can be expected to continue, as the area underlain by London Clay is still considered prime for development: the research findings should then be applicable to future construction works. In this paper, the London Clay is treated as a single statistical population, as justified by the following consideration of the deposit.

London Clay is an overconsolidated, stiff, fissured clay. It is considered to be reasonably uniform, and its properties have been extensively investigated. It is a blue or grey clay that weathers to brown, it contains fossils resembling modern warm-water forms, and it can contain bands of concretions as well as pyrite or selenite crystals. ${ }^{17}$ 
The behaviour of bored piles in London Clay has been described by Skempton. ${ }^{18}$ Skempton analysed pile load tests at 10 sites, and summarised extensive data relating to the strength of London Clay. These strength data are based on tests of undisturbed samples of $38 \mathrm{~mm}$ diameter. Modern site investigation techniques utilise $100 \mathrm{~mm}$ diameter undisturbed samples because of the increased likelihood of intercepting a natural fissure and hence obtaining a representative, fissured, shear strength. Patel ${ }^{19}$ re-analysed the results presented by Skempton, ${ }^{18}$ and Whitaker and Cooke, ${ }^{20}$ and added further results of investigations at 23 sites across the London Basin.

London Clay is a relatively consistent and uniform geological deposit; there is, however, variation between sites, which leads to the need for individual consideration and site-specific investigation. ${ }^{19}$ These differences can be partially explained by considering the history of the strata: the sequence of sedimentation, erosion and weathering.

King $^{21}$ describes how the marine sedimentation of the London Clay was affected by changes in sea level during the deposition, a fall in sea level being associated with coarsergrained material being deposited. The London Clay can be divided into five successive lithological units, which reflect the cyclical changes in the depositional environment. Engineering properties can be discontinuous across the boundaries between the lithological units: hence there is merit in knowing the relative positions of the divisions and interpreting property profiles accordingly. In the case of undrained shear strength, however, there is no discernible discontinuity: ${ }^{22}$ there is therefore no justification for the additional site investigation necessary to identify the lithological units for a statistical assessment.

Post deposition, the London Clay has been subjected to a complex loading regime. Continuing deposition led to the London Clay being deeply buried. Subsequent erosion of these deposits and of the London Clay during the late Tertiary and Pleistocene times led to the surviving clay being heavily overconsolidated. The extent of this erosion has been estimated to be a thickness of between 150 and $300 \mathrm{~m} \cdot .^{23-25}$ In places, there has been further re-covering of the London Clay with river terrace deposits (sands and gravels) as well as with alluvial deposits. Skempton ${ }^{18}$ observed some softening of the clay where there had been erosion and subsequent re-covering with alluvial material, and made a correction to sample depth for samples from such areas based on the relative density of overlying materials, but only to depths of about $15 \mathrm{~m}$ below ground level. Conversely, Patel ${ }^{19}$ used only straight-line regressions for mean shear strength profiles. Inspection of the data collated for the current paper did not reveal clear evidence for special treatment of the clays that had been covered by alluvial deposits: they are therefore included in their original form, and straight-line regressions are performed to obtain profiles of mean shear strength against depth.

De Freitas ${ }^{26}$ suggests that faulting may also influence the continuity of properties across the basin. The location of faults (and the suggested network of minor faults that would result from the brittle behaviour of the clay) has not been mapped. It is therefore currently impossible to determine the effect that this has on the spatial variability of engineering properties. The lithology may not be continuous, but as this has been observed not to have an effect on strength, and as regional trending of the data has not been observed by the authors, the data have been treated as a continuous set.

The weathering of London Clay is apparent to differing depths across the London Basin. Where the clay has been covered with terrace deposits these have afforded some protection, and the weathered zone tends to extend to only about $1 \mathrm{~m}$ below the top of the clay; elsewhere the weathering may be apparent to depths of $10 \mathrm{~m}$. Chandler and Apted ${ }^{27}$ have investigated the effect of weathering on the strength of London Clay. Their results show a change in the strength in effective stress terms: this is related to an apparent reduction in the overconsolidation ratio. In this study the undrained strength is of interest, and inspection of the data revealed that allowance for the weathering of the London Clay did not lead to a significant difference in the mean shear strength profile.

\section{QUANTIFYING EXPERIENCE AND PRIOR KNOWLEDGE}

Consideration of previous knowledge and experience can assist in obtaining characteristic values that better represent the site conditions or provide greater confidence. In order to apply the objective methods introduced in this paper, a quantification of the existing knowledge or experience is required. In the following section, information relating to the shear strength of London Clay is collated and processed by way of an example of how prior knowledge might be quantified for use in such calculations and characterisation. The information is also useful for probabilistic analysis and design of piles, as shown in the case studies.

\section{I. Construction of database for shear strength of London Clay}

In order to quantify existing knowledge relating to the mean value and variation of shear strength of London Clay, a database of site investigation data has been constructed. The data presented in this paper are drawn from 68 sites in the London Basin, predominantly in the Greater London area: the locations of the sites are shown in Fig. 3. There were results from 947 quick undrained triaxial compression tests conducted

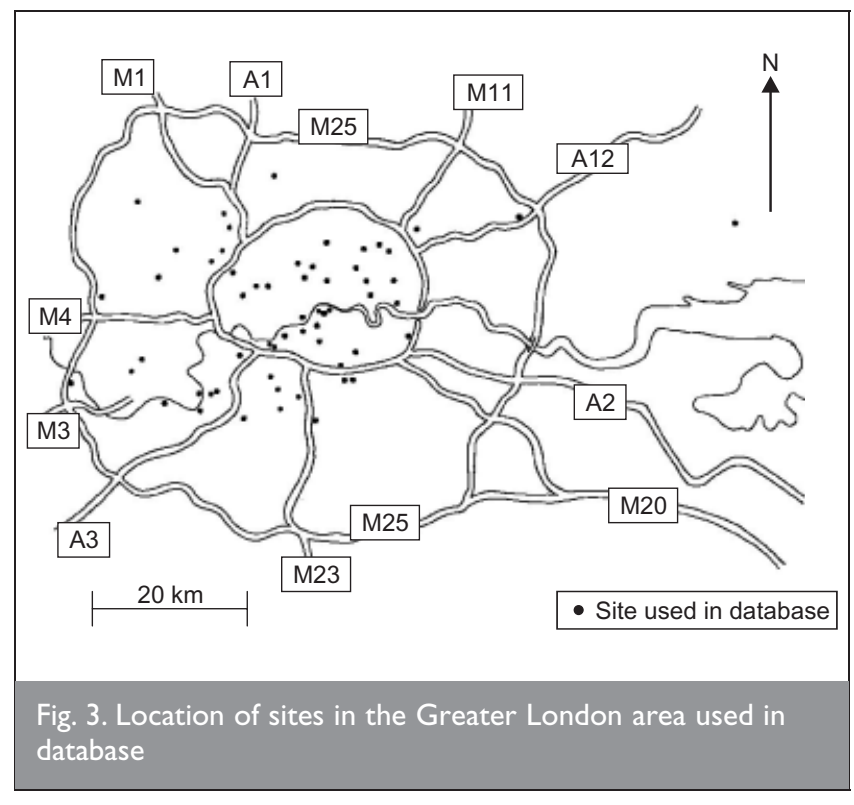


on undisturbed samples from 234 boreholes. The data are drawn from investigations by 31 different SI contractors carried out for piling contracts between 2003 and 2006. There were between 1 and 11 boreholes at each site with shear strengths reported from between 1 and 24 samples per borehole. Sites have been selected where $100 \mathrm{~mm}$ diameter undisturbed samples were taken from the London Clay for quick undrained triaxial testing.

Shear strengths are recorded against depth below site ground level. The depth to the top of the London Clay is also recorded for each borehole. An example of the strength/depth data for one typical site is shown in Fig. 4 with a linear regression trend line; the 37 triaxial test results are from samples taken from 8 boreholes.

If the collated data from all 68 sites are treated as a single continuous dataset, a regression line can be used to describe the mean value of shear strength of the London Clay with depth. A linear trend for strength against depth below ground surface for the entire dataset is shown in Fig. 5; a straight line regression has been performed on the data using the method of least squares. The equation of the line is $c_{\mathrm{u}}=6 \cdot 1 d+60 \cdot 0 \mathrm{kN} / \mathrm{m}^{2}$, where $c_{\mathrm{u}}$ is the undrained shear strength, and $d$ is the depth below ground level: the fit of the line to the data has a correlation coefficient $\left(R^{2}\right)$ of $0 \cdot 43$. A straight line has been chosen as this provides the simplest representation of the data. This approach is consistent with previous studies. ${ }^{15,19,20}$ Other

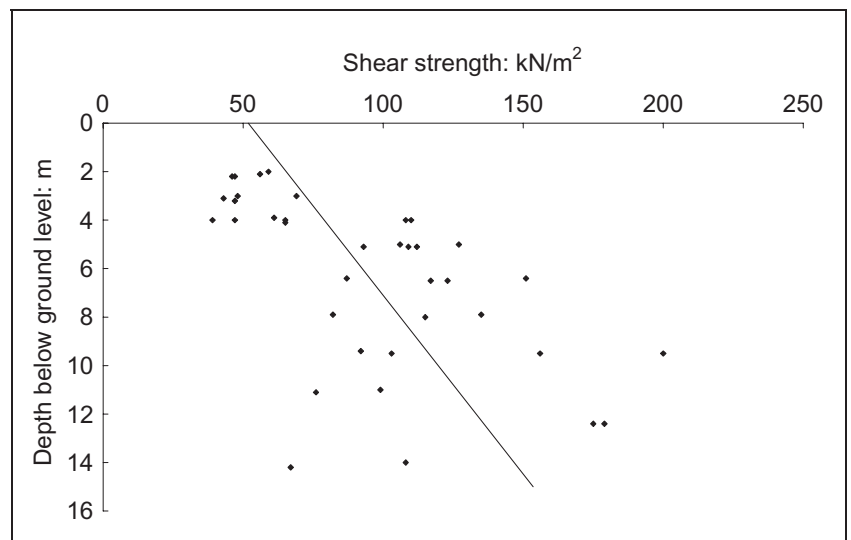

Fig. 4. Example shear strength data, with linear regression trend line, from site investigation at a site near Woolwich

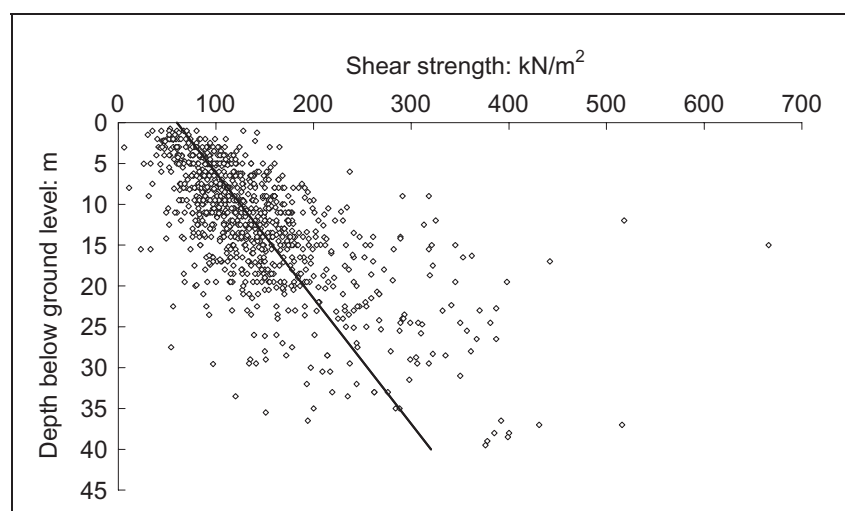

Fig. 5. Shear strength against depth for all sites in the dataset, with trend line types of line (power, logarithmic, exponential and polynomial) do not provide significantly greater correlation.

The collated data can be compared with existing published data for the undrained shear strength of London Clay. Patel ${ }^{19}$ used the top of the London Clay as a reference point, rather than ground level, and to facilitate direct comparison the data from this study have been converted into this format. Fig. 6 shows mean regression lines of the strength with depth below the top of the clay for four example sites, along with the mean data for the whole dataset presented in this paper, and overlain on this is the envelope of the mean lines presented by Patel ${ }^{19}$ for 23 different sites across the London basin. The mean regression line of the data collected in this study is observed to be close to the middle of the range reported by Patel: ${ }^{19}$ this is consistent with the assumption of normal distribution of shear strength. The individual mean regression lines for single sites shown in this example also fall within the range. The data presented and used in this study are consistent with those previously reported.

An additional benefit of the data presented in this paper is that information relating to the distribution of the data is also available, thus allowing estimates of the coefficient of variation to be made. The size of the database means that it can be assessed and manipulated using statistical techniques. Information relating to the distribution and variation also permits probabilistic analysis to be performed as an alternative or in addition to traditional deterministic analysis.

\subsection{Data processing}

The data in their raw format, or simply summarised by a regression line, cannot be easily employed as prior knowledge to update site-specific information using the techniques described in Section 2.2. A method of processing the data is required such that a mean and a measure of the distribution can be readily obtained for use in Bayesian updating. The method proposed is to group the strength data by depth to top of sample, and to calculate summary statistics for each group. Bands of $1 \mathrm{~m}$ thickness have been used for the grouping; depths have been measured from ground level. The summary statistics and the number of sites and data points used to generate them are shown in Table 1 . The mean values for each band are plotted in Fig. 7, overlaid by the mean regression line found previously for all test results (first shown in Fig. 5), and a reasonable fit can be observed, particularly for depths between 0 and $20 \mathrm{~m}$, where a greater number of data points are

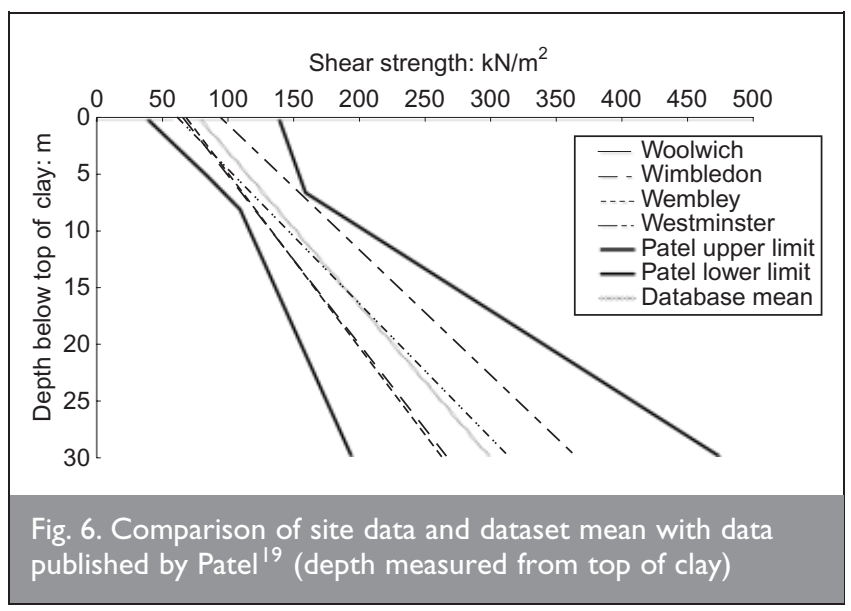




\begin{tabular}{|c|c|c|c|c|c|}
\hline $\begin{array}{l}\text { Nominal } \\
\text { depth: } m\end{array}$ & $\begin{array}{l}\text { Depth } \\
\text { range: } \mathrm{m}\end{array}$ & $\begin{array}{l}\text { Number of } \\
\text { sites }\end{array}$ & $\begin{array}{l}\text { Number of } \\
\text { test results }\end{array}$ & $\begin{array}{c}\text { Mean shear strength, } \\
X_{\mathrm{m}}: \mathrm{kN} / \mathrm{m}^{2}\end{array}$ & $\begin{array}{l}\text { Coefficient of } \\
\text { variation, } V_{x}\end{array}$ \\
\hline 1 & $0.5-1.5$ & 9 & 12 & $70 \cdot 67$ & 0.46 \\
\hline 2 & $1.5-2.5$ & 14 & 28 & 64.43 & 0.36 \\
\hline 3 & $2 \cdot 5-3 \cdot 5$ & 23 & 38 & $78 \cdot 24$ & 0.38 \\
\hline 4 & $3 \cdot 5-4 \cdot 5$ & 20 & 42 & $86 \cdot 31$ & 0.26 \\
\hline 5 & $4 \cdot 5-5 \cdot 5$ & 34 & 57 & 92.89 & 0.29 \\
\hline 6 & $5 \cdot 5-6 \cdot 5$ & 20 & 31 & $109 \cdot 42$ & 0.36 \\
\hline 7 & $6 \cdot 5-7 \cdot 5$ & 27 & 42 & $112 \cdot 12$ & 0.25 \\
\hline 8 & $7 \cdot 5-8 \cdot 5$ & 43 & 67 & $107 \cdot 22$ & 0.34 \\
\hline 9 & $8 \cdot 5-9.5$ & 25 & 38 & 131.58 & 0.41 \\
\hline 10 & $9.5-10.5$ & 34 & 58 & 119.84 & 0.31 \\
\hline II & $10.5-11.5$ & 42 & 71 & 126.19 & 0.32 \\
\hline 12 & $11.5-12.5$ & 23 & 39 & 154.26 & 0.50 \\
\hline 13 & $12.5-13.5$ & 31 & 49 & 132.04 & 0.32 \\
\hline 14 & $13.5-14.5$ & 39 & 64 & $|44.4|$ & 0.36 \\
\hline 15 & $14.5-15.5$ & 25 & 40 & 185.06 & 0.51 \\
\hline 16 & $15 \cdot 5-16.5$ & 19 & 29 & $157 \cdot 17$ & 0.48 \\
\hline 17 & $16.5-17.5$ & 21 & 37 & $|6| \cdot 8 \mid$ & 0.45 \\
\hline 18 & $17 \cdot 5-18.5$ & 13 & 22 & 166.82 & 0.35 \\
\hline 19 & $18.5-19.5$ & 18 & 24 & 171.46 & 0.33 \\
\hline 20 & $19.5-20.5$ & 20 & 37 & 170.33 & 0.39 \\
\hline 21 & $20 \cdot 5-21 \cdot 5$ & 10 & 14 & 176.46 & 0.33 \\
\hline 22 & $21 \cdot 5-22 \cdot 5$ & 2 & 7 & 216.29 & 0.36 \\
\hline 23 & $22 \cdot 5-23 \cdot 5$ & 10 & 20 & 210.53 & 0.41 \\
\hline 24 & $23 \cdot 5-24 \cdot 5$ & 9 & 13 & 220.85 & 0.30 \\
\hline 25 & $24 \cdot 5-25 \cdot 5$ & 5 & 10 & 293.40 & 0.16 \\
\hline 26 & $25 \cdot 5-26 \cdot 5$ & 2 & 7 & $229 \cdot 57$ & 0.38 \\
\hline 27 & $26 \cdot 5-27 \cdot 5$ & I & 4 & $291 \cdot 50$ & 0.36 \\
\hline 28 & $27 \cdot 5-28 \cdot 5$ & 2 & 7 & 227.00 & 0.47 \\
\hline 29 & $28 \cdot 5-29.5$ & 5 & 8 & $228 \cdot 13$ & 0.33 \\
\hline 30 & $29 \cdot 5-30 \cdot 5$ & 3 & 7 & $204 \cdot 29$ & 0.42 \\
\hline
\end{tabular}

to have normal

distributions, ${ }^{28}$ Van Alboom and Menge ${ }^{12}$ warn that for some parameters log-normal distribution may be more appropriate. Hooper and Butler, ${ }^{16}$ however, demonstrated that the variation of shear strength (from laboratory test results) is well represented by a normal distribution. A subjective assessment of the data used in this paper can be carried out by inspecting the distribution of the test results. The strengths are first normalised for depth using the equation of the mean regression line. This normalised distribution is shown in Fig. 9, with the normal distribution predicted from the mean and standard deviation. The distribution is observed to be close to normal, and there is no indication of significant deviation that would suggest that an alternative distribution would be more apt. Detailed examination of

available. The deviations that occur below $20 \mathrm{~m}$ are likely to be a result of the low number of test results available at these depths, as many boreholes used to build the database did not extend below $20 \mathrm{~m}$, as indicated in Table 1 .

The coefficients of variation shown in Table 1 and Fig. 8 are in general agreement with those reported in previous literature. ${ }^{13,15,16}$

\subsection{Data distribution}

The Bayesian updating relies upon the data having a normal distribution. While most geotechnical parameters can be shown

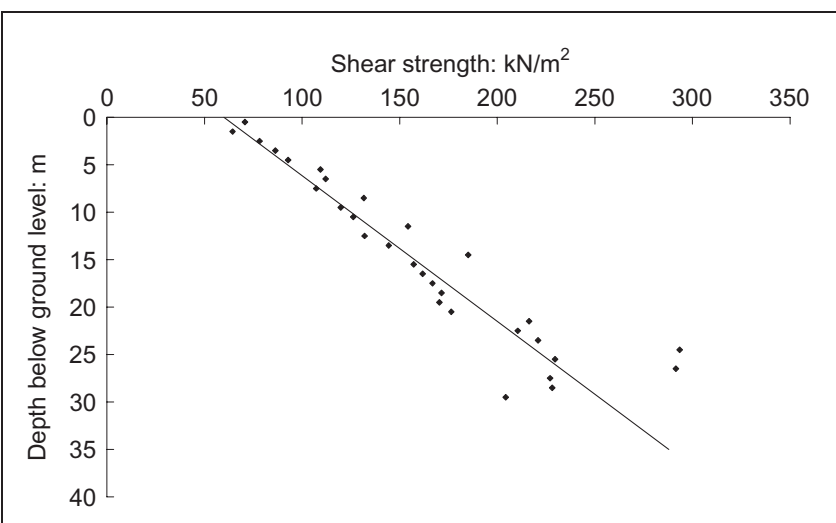

Fig. 7. Mean values for shear strength grouped into I $\mathrm{m}$ thick depth bands, shown with the original regression line for all data points the form of the distribution and the effect of an assumption of normal, or other, distribution is beyond the scope of this paper.

\section{APPLICATION OF QUANTIFIED EXPERIENCE: CASE STUDIES}

\section{I. Bayesian updating}

The information collated in the database can be used as prior knowledge to refine, or update, the derived values for soil properties from a site-specific investigation, using Bayesian techniques as proposed by Tang. ${ }^{8}$ The process is illustrated through application to a case study of pile design.

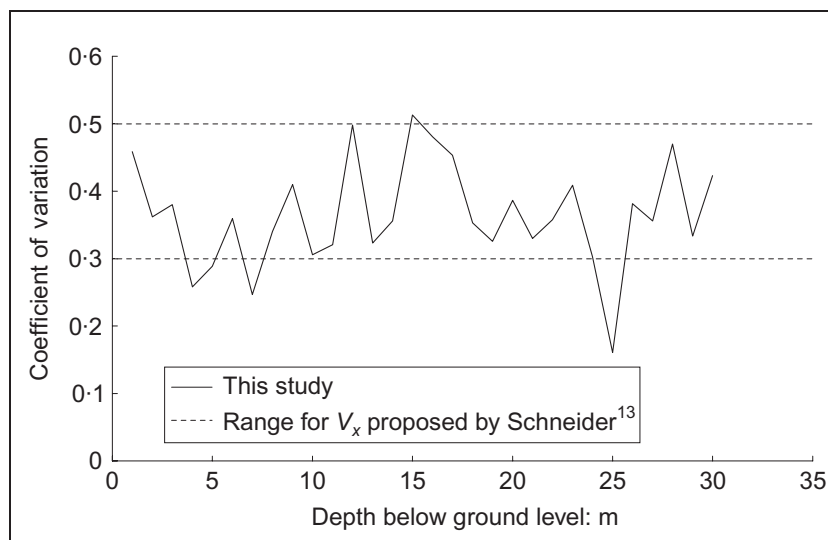

Fig. 8. Coefficient of variation (standard deviation/mean) for the gathered data as grouped into I $\mathrm{m}$ depth bands compared with published data ${ }^{13}$ 


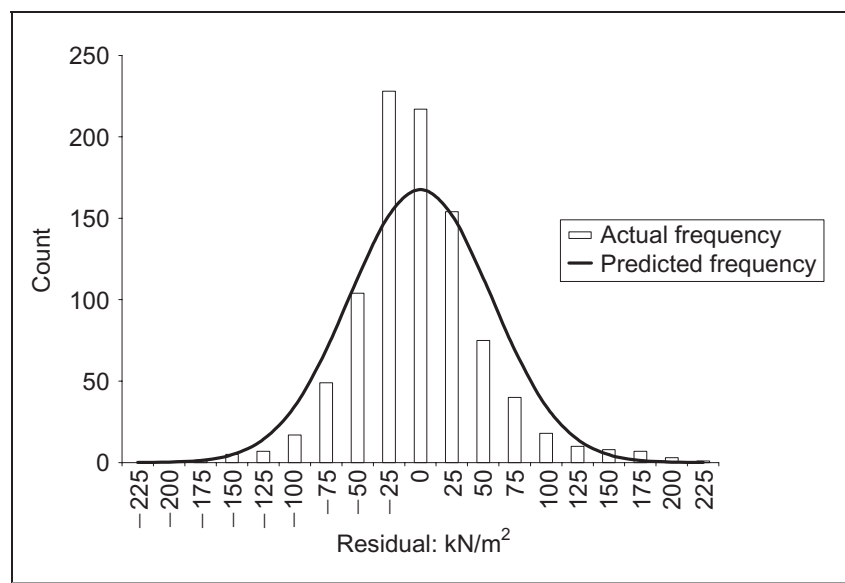

Fig. 9. Distribution of shear strength test data (about the mean regression line with depth) from the London Clay database compared with the predicted normal distribution

Shear strength is assumed to be normally distributed, with mean $\mu^{\prime}$ and standard deviation $\sigma^{\prime}$. The site-specific testing data were used to estimate the summary statistics for the site. A regression can be carried out to estimate the average at a particular depth $\bar{x}$ and the standard deviation $\sigma$, and again a normal distribution was assumed.

The site for this case study is located near to Woolwich, South East London. The site investigation consisted of eight boreholes, from which 37 samples were tested in quick undrained triaxial tests. There were no appreciable superficial deposits reported; London Clay is present from just below the surface to an unproven depth beyond the investigation limits and anticipated pile toe depths. The test results are shown, with mean regression line, in Fig. 4. The equation of the mean regression line for the site data is $c_{\mathrm{u}}=6 \cdot 8 d+51 \cdot 8 \mathrm{kN} / \mathrm{m}^{2}$.

It is important at this stage to consider the choice of a leastsquares regression line to represent the data. An experienced engineer may question the position of this line for several reasons, such as the grouping of values at shallow depth, which all lie below the line, or the large spread of values at greater depth. Using an engineering judgement approach to construct a line, extreme values may be investigated for sampling errors and be subsequently omitted, or different weighting may be given to some of the points (such as the cluster at shallow depth). In the objective approach advocated in this paper, there is no room for such subjective weighting of data. A straight line is used as this is the same as that found for the much larger database, as shown in Fig. 5. A bilinear summary of the data might seem intuitive because of the low strengths at shallow depth; however, the premise of this approach is that the site-specific results are from the same population as the larger database, and the straight line can therefore be used to represent this data. Errors may be introduced by the inclusion of all data including the extreme values. The influence of these errors is minimised, however, by applying equal significance to each data point and incorporating the additional data from other sites in the same statistical population through Bayesian updating. It must be stressed that engineering judgement is not completely removed from this process, and it should not be applied blindly. The critical application of engineering judgement is in deciding on a suitable database of existing knowledge, and in the decision as to whether or not the site in question is really part of the same statistical population.

The data from the site-specific investigation are refined using the set of data described in Section 3.1. Each test result is updated in turn following the method discussed in Section 3.2 and illustrated by the example below.

At $2 \mathrm{~m}$ below ground level (the depth of the first sample point), the estimated mean strength $\bar{x}$ from the mean regression line is $65 \cdot 4 \mathrm{kN} / \mathrm{m}^{2}$. This is based on a linear regression of the 37 undrained shear strengths against depth, using the method of least squares. The average coefficient of variation for the site, $v$, has been calculated as $0 \cdot 3$. The standard deviation is found as the product of the coefficient of variation and the mean. The standard deviation for the site at $2 \mathrm{~m}$ is $19.6 \mathrm{kN} / \mathrm{m}^{2}$. The prior information is sourced from the database of results, which have been grouped into $1 \mathrm{~m}$ thick bands. The data from the $1.5-2.5 \mathrm{~m}$ band are therefore used for this calculation. From the database, the global mean at this depth is $64 \cdot 4 \mathrm{kN} / \mathrm{m}^{2}$; the standard deviation is $23 \cdot 3 \mathrm{kN} / \mathrm{m}^{2}$. Applying equations (1) and (2) provides a posterior mean, at $2 \mathrm{~m}$, of $65.0 \mathrm{kN} / \mathrm{m}^{2}$ and a standard deviation of $15.0 \mathrm{kN} / \mathrm{m}^{2}$. This process can be repeated for each test sample location, and this produces the profile of posterior undrained shear strength against depth shown in Fig. 10. The site-specific profile (derived values) and their trend line are also shown for comparison. The effect of applying the Bayesian updating technique is to produce a new mean profile for the site that is closer to the mean for the global population.

\subsection{Determination of characteristic values}

Using the approximation proposed by Schneider, ${ }^{13}$ characteristic values can be obtained from the summary statistics (mean and standard deviation) defined in Section 4.1.

In the case study example, the posterior mean $\mu^{\prime \prime}$ at $2 \mathrm{~m}$ depth is $65.0 \mathrm{kN} / \mathrm{m}^{2}$, and the standard deviation is $15 \cdot 0 \mathrm{kN} / \mathrm{m}^{2}$ (which leads to a coefficient of variation $V_{x}$ of $0 \cdot 24$ ). Using equation (3) this gives a characteristic value of $57 \cdot 5 \mathrm{kN} / \mathrm{m}^{2}$. This process can be repeated for each value, successively modifying each of the points in Fig. 7 that represent the derived values to generate a characteristic value. These values can be described by a linear trend shown in Fig. 11, the equation of which is $c_{\mathrm{u}}=65 \cdot 7 d+51 \cdot 2 \mathrm{kN} / \mathrm{m}^{2}$.

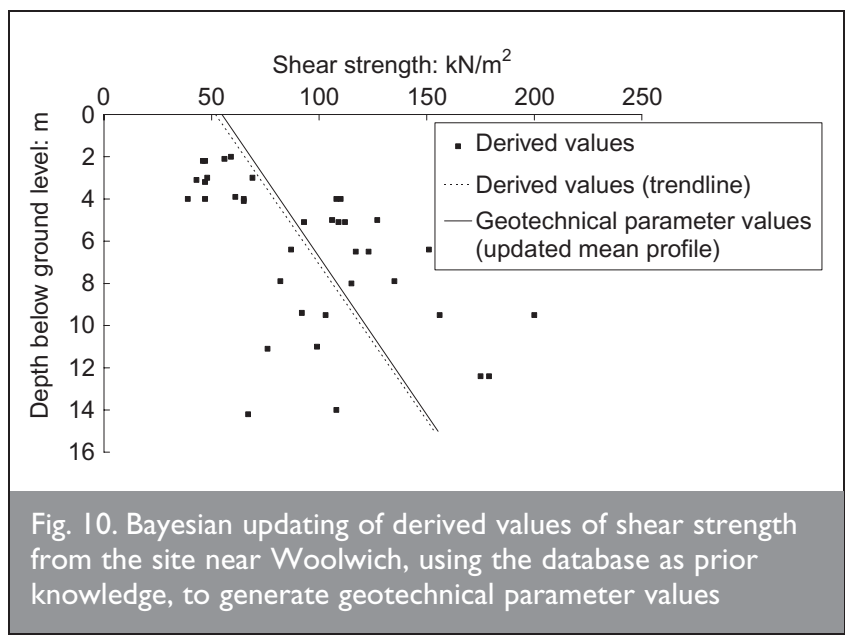




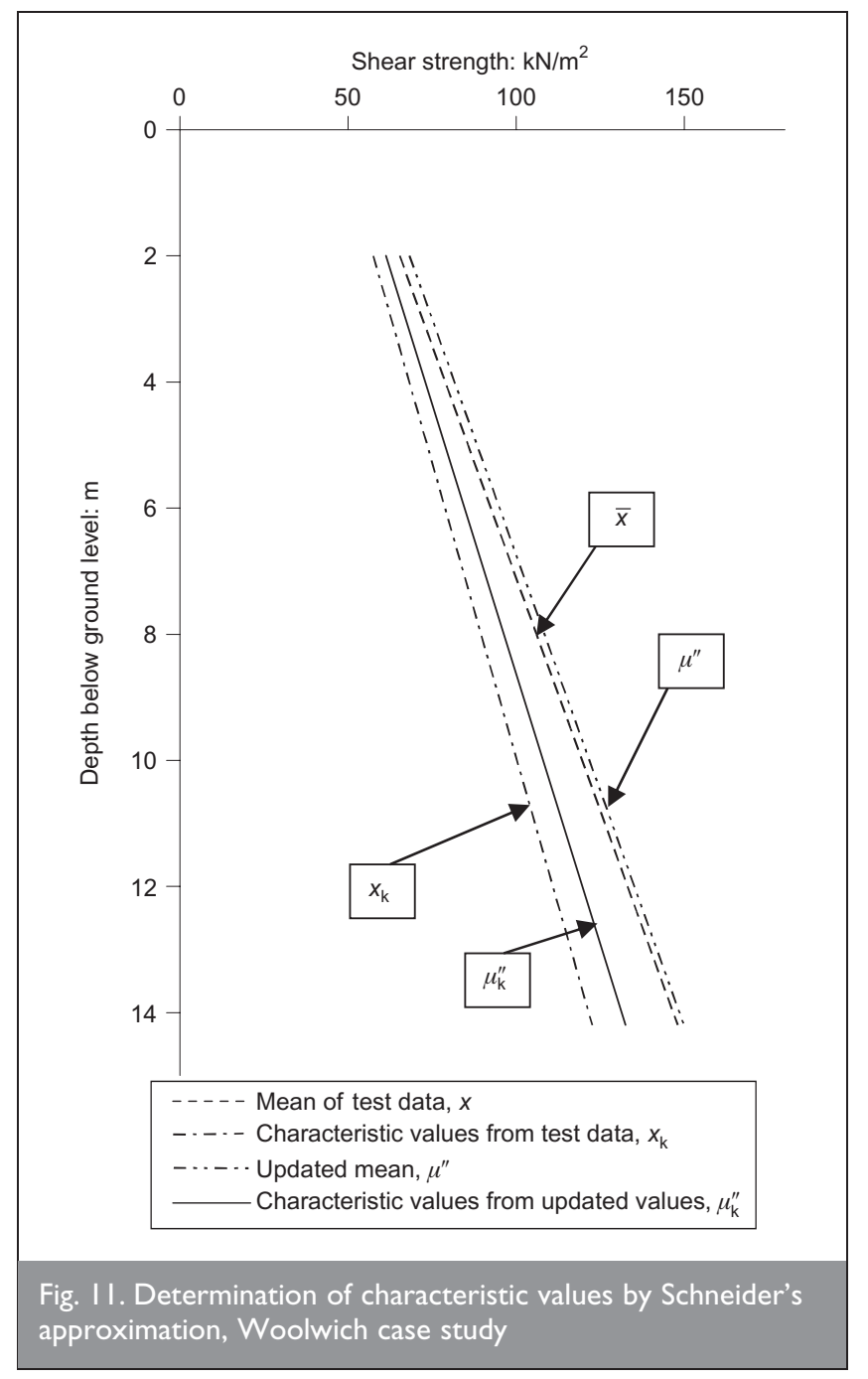

For comparison, the approximation by Schneider ${ }^{13}$ has been applied to the test data without updating using the database information. The characteristic values obtained from the updated mean values are higher, partly because of the increase in the mean that resulted directly from the updating, but also because of the smaller coefficient of variation associated with the updated values. This is evident from the smaller difference between the mean and characteristic regression lines for the data that have been updated, compared with the equivalent difference for the data that have not been updated.

\subsection{Significance for design}

An example pile design at the site of the case study demonstrates the effect of this updating process. To carry a compressive load of $350 \mathrm{kN}$, a typical solution would utilise continuous flight auger piles of $500 \mathrm{~mm}$ diameter. Such a pile would need to be $14 \mathrm{~m}$ long (measured from ground level) using the unrefined values. In this design it is assumed that there is no contribution to shaft capacity from the overlying fill material (which extends to $2 \mathrm{~m}$ below ground level), and the adhesion factor $\alpha$ is taken as 0.5 in the London Clay. If the updated values of shear strength are used, the pile would need to be $13.2 \mathrm{~m}$, that is, $800 \mathrm{~mm}$ shorter. The cumulative volume saved over a number of piles (120 in the case of this example) would produce significant cost savings in terms of materials volume ( $18.9 \mathrm{~m}^{3}$ of concrete) and time for construction. Savings are of the order of 3-4\% of the actual pile construction costs. Although such significant savings might have been found by fine-tuning and manipulating subjective interpretations of the variables based on experience and engineering judgement (e.g. selection of design line through site shear strength data), the approach presented in this paper allows such savings to be found in a justifiable, objective manner.

The application of Bayesian updating has the effect of moving the site mean towards that of the collated database mean. In the above example this gives a higher strength at any given depth than for the untreated site data, and hence shorter pile lengths are obtained.

A second case study shows an example of where the derived values are lower following Bayesian updating than for the untreated site data. The site for this example is in Wimbledon, South West London. The site investigation consisted of 7 boreholes, from which 15 samples were tested. As in the previous example the London Clay is present from just below ground level to an unproven depth beyond the area of interest. The equation of the mean regression line for the site data is $c_{\mathrm{u}}=9 \cdot 3 d+61 \cdot 7 \mathrm{kN} / \mathrm{m}^{2}$. Fig. 12 shows the mean of the test data, the updated mean values and their associated characteristic values, calculated following the same procedure as in the previous example. In this case there would not be direct savings related to a reduction in the pile length, as seen above, but increased costs. The resulting increase in confidence, however, is discussed below.

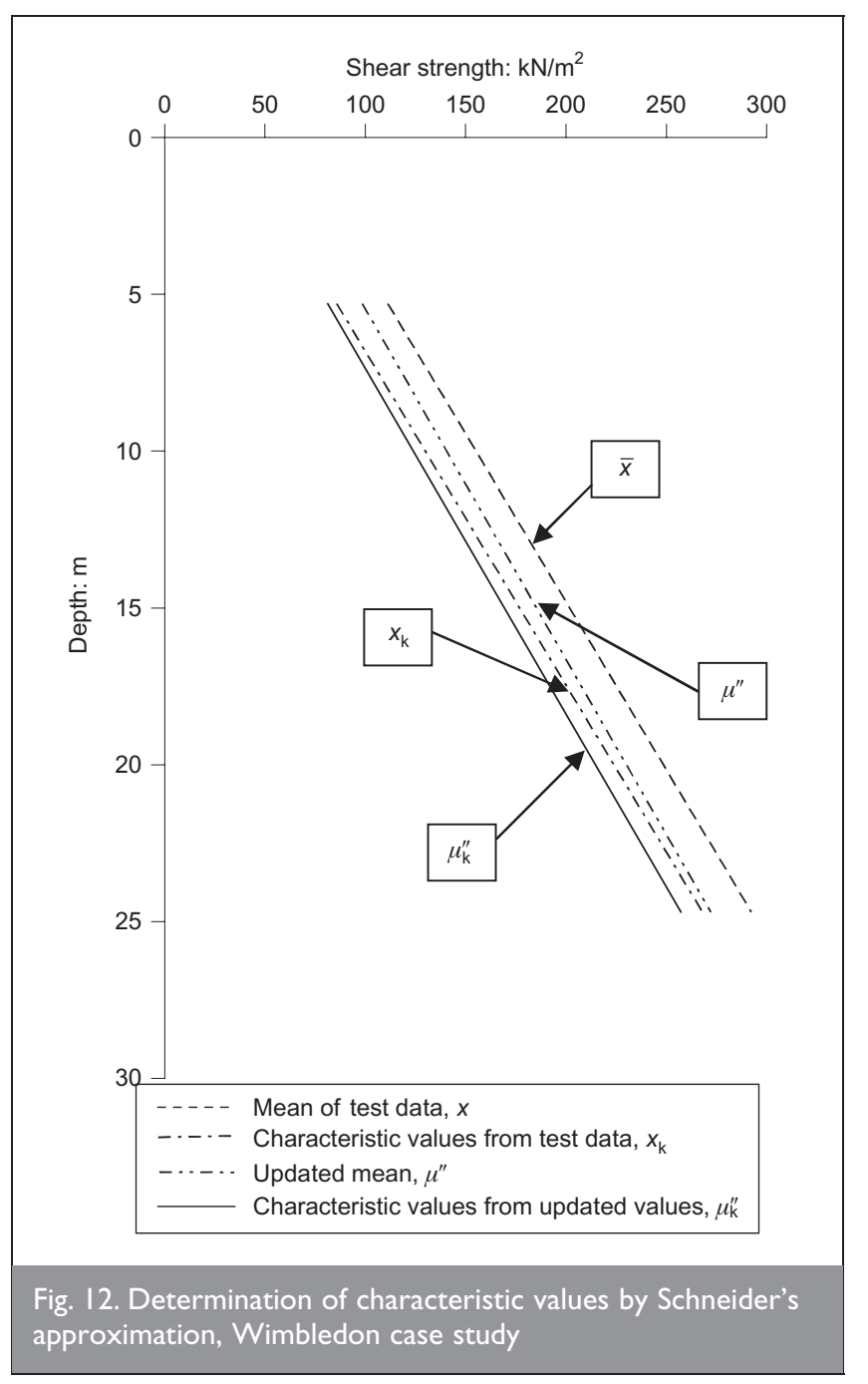




\section{DISCUSSION}

It is essential for the engineer to make a judgement regarding the applicability of Bayesian updating before deciding whether to apply the technique. An assessment must be made of whether the site-specific results are from the same population as the database. Where there are significant departures from the database mean values, it should be investigated whether there is a reasonable explanation, such as sampling difficulties. The engineer's judgement remains vital and the techniques presented here should be used as a tool to aid and quantify those judgements.

Bayesian updating can lead to direct savings, as demonstrated in the first case study in this paper, which resulted in cost savings of $3-4 \%$. The mean values may, however, be reduced by the updating process. The coefficient of variation will also reduce, and this will to some extent counterbalance a decrease in the mean when the characteristic values are calculated. Moreover, application of Bayesian updating leads to a better estimate of the soil properties. Adopting the updated soil strength profile leads to a solution with a lower probability of failure, and hence less risk is associated. A probabilistic comparison of alternative solutions can then be made and the most appropriate can be selected. Duncan ${ }^{29}$ provides a simple framework for probabilistic comparison of alternative solutions. The product of the reduction in probability of failure associated with more reliable design and the cost of failure should be set against the additional cost of adopting the more reliable design. In terms of piled foundations, the cost of failure could be the cost of constructing additional foundations following the failure of a test pile; more dramatically, and more likely given the small number of piles that are routinely tested, the cost of failure could be that of remedial works to underpin a structure that has settled by an excessive amount. The question of what constitutes an acceptable probability of failure is subjective, and may be specific to the project and its interested parties.

\section{CONCLUSIONS}

The determination of ground conditions at a site and subsequent modelling of these conditions, allowing for variation and the nature of the interaction between the soil and structure, are fundamental in geotechnical design and is reliant upon the skill of the engineer. The inclusion of previous experience and existing knowledge is an important step in the process of characterising ground conditions, as cost and practicalities can lead to even a well-planned site investigation yielding only limited information. Wider experience and knowledge from sites with similar conditions are required to obtain statistical estimates of geotechnical properties. Prior information is often incorporated into the assessment of the soils for design by subjective means, and while this remains a valid approach, objective methods may be called for.

One possible way to include prior knowledge quantitatively is to employ Bayesian updating. Where a property, such as shear strength, increases with depth, a method of grouping data into bands has been applied, enabling summary statistics to be calculated for use in the updating. The outputs of the updating process, namely a revised mean and standard deviation, can be used to describe the statistical distribution of properties and to better assess characteristic values. The effect of carrying out
Bayesian updating on a set of site investigation data is to produce a revised mean that is a function of the site-specific data and the prior information, and which is weighted by their relative variations. Bayesian updating leads to more rigorous estimate of the soil properties, which would lead to a lower likelihood of failure and a solution with less risk attached. This is of great interest to the engineer, particularly if probabilistic comparisons of alternative solutions are to be made.

A large database of the shear strength of London Clay, from 947 quick undrained triaxial compression tests, has been collated and provides a description of the distribution of strengths at a given depth below ground level. Such a database can be used as a quantitative source of prior information in the Bayesian updating process described. Analysis of the database suggests that the coefficient of variation for the shear strength is in the range $0 \cdot 2-0 \cdot 5$. A linear relationship between mean shear strength and depth has been assumed. The distribution of test values around this has been observed to approximate a normal distribution.

Further work on this topic could investigate similar trends and distributions for other properties of soils, or include shear strength data obtained using other site investigation techniques, such as the commonly used standard penetration test. Similar data gathering and analysis for other soils, soil types and regions would also be beneficial in providing prior data for geotechnical design. Sources of prior data are readily available in practice. Engineers and contractors could make use of the large data resources that they hold from previous works to build databases similar to that described in this paper, and to generate the necessary summary statistics.

\section{ACKNOWLEDGEMENTS}

This work forms part of a research programme being undertaken at the Centre for Innovative and Collaborative Engineering (CICE), Loughborough University, in association with Rock and Alluvium Ltd, and is supported by the UK Engineering and Physical Sciences Research Council.

\section{REFERENCES}

1. EUROPEAN COMmitTeE FOR StANDARdisation. Geotechnical Design-General Rules. BSI, Milton Keynes, 2001, BS EN 1997-1.

2. Simpson B. and DRISColl R. (eds). Eurocode 7: A Commentary. Construction Research Communications, London, 1998.

3. ORR T. L. L. Probabilistic characterization of Irish Till properties. Proceedings of a Conference on Risk and Reliability in Ground Engineering. Thomas Telford, London, 1993, pp. 126-133.

4. Frank R., Bauduin C., Driscoll R., Kavvadas M., Krebs OVESEN N., ORR T. and SCHUPPENER B. Basis of geotechnical design. In Designers' guide to EN 1997-1. Eurocode 7: Geotechnical Design-General Rules. Thomas Telford, London, 2004, pp. 19-52.

5. Stroud M. A. and Butler F. G. The standard penetration test and the engineering properties of glacial materials. Proceedings of a Symposium on Engineering Properties of Glacial Materials. Midland Soil Mechanics and Foundation Engineering Society, 1975, pp. 117-128.

6. LONDON District SURVEYORS AsSOCIATION. Guidance Notes for 
the Design of Straight Shafted Bored Piles in London Clay. LDSA Publications, Bromley, 2000, Guidance Note 1.

7. LUMB P. The variability of natural soils. Canadian Geotechnical Journal, 1966, 3, No. 2, 74-97.

8. TANG W. H. A Bayesian evaluation of information for foundation engineering design. Proceedings of the 1st International Conference on Applications of Statistics and Probability to Soil and Structural Engineering, Hong Kong, 1971, 173-185.

9. Dixon N., Blumel W., Stoewahse C., Kamugisha P. and JoNES J. R. V. Geosynthetic shear behaviour: Part 2 characteristic values for use in design. Ground Engineering, 2002, 35, No. 3, 49-53.

10. FranK R., Bauduin C., Driscoll R., Kavvadas M., Krebs OVESEN N., ORR T. and SCHUPPENER B. Geotechnical data. In Designers' guide to EN 1997-1. Eurocode 7: Geotechnical Design-General Rules. Thomas Telford, London, 2004, pp. 53-60.

11. British Standards Institution. Code of Practice for Foundations, BSI, Milton Keynes, 1986, BS 8004.

12. Van Alboom G. and Menge P. The derivation of the characteristic values of shear strength parameters according to EC7. Proceedings of the 12th European Conference on Soil Mechanics and Geotechnical Engineering, Amsterdam, 1999, 1, 295-302.

13. SCHNEIDER H. R. Definition and determination of characteristic soil properties. Proceedings of the 14th International Conference on Soil Mechanics and Geotechnical Engineering, Hamburg, 1997, 4, 2271-2274.

14. D'Agostino R. B. and StePhens M. A. Goodness-of-Fit Techniques. Marcel Dekker, New York, 1986.

15. HoOPer J. A. and BUTLER F. G. Some numerical results concerning the shear strength of London Clay. Géotechnique, 1966, 16, No. 4, 282-304.

16. PHOON K. K. and KULHAWY F. H. Characterization of geotechnical variability. Canadian Geotechnical Journal, 1999, 36, No. 4, 612-62

17. BLYTH F. G. H. A Geology for Engineers, 4th edn. Edward Arnold, London, 1960.

18. SKempton A. W. Cast in-situ bored piles in London Clay. Géotechnique, 1959, 9, No. 4, 153-173.

19. PATEL D. C. Interpretation of results of pile tests in London
Clay. Proceedings of a Conference on Piling: European Practice and Worldwide Trends. Thomas Telford, London, 1992, pp. 100-110.

20. WhitAKer T. and COOKe R. W. An investigation of the shaft and base resistances of large bored piles in London Clay. Proceedings of a Symposium on Large Bored Piles, Institution of Civil Engineers, London, 1966, pp. 7-49.

21. KING C. The Stratigraphy of the London Basin and Associated Deposits, Tertiary Research Special Paper, Backhuys, Rotterdam, 1981.

22. Hight D. W., McMillan F., Powell J. J. M., Jardine R. J. and Allenou C. P. Some characteristics of London Clay. Characterisation of Engineering Properties of Natural Soils (TAN T. S., Phoon K. K., Hight D. W. and LeroueIL S (eds)). Balkema, Rotterdam, 2002, pp. 851-908.

23. SKEMPTON A. W. Horizontal stresses in an overconsolidated Eocene clay. Proceedings of the 5th International Conference on Soil Mechanics and Foundation Engineering, Paris, 1961, 1, 351-357.

24. Bishop A. W., WeBB D. L. and LeWIN P. I. Undisturbed samples of London Clay from the Ashford Common shaft: strength-effective stress relationships. Géotechnique, 1965, 15, No. 1, 1-31.

25. CHANDLER R. J. Clay sediments in depositional basin: the geotechnical cycle. Quarterly Journal of Engineering Geology and Hydrogeology, 2000, 33, No. 1, 7-39.

26. DE FreITAS M. H. Evidence for the compartmentalisation of the London Basin. Proceedings of a Joint Meeting of the Thames Valley Regional Group and the Engineering Group of the Geological Society on the Engineering Geology of the London Clay, Egham, 2007.

27. ChANDLER R. J. and APTED J. P. The effect of weathering on the strength of London Clay. Quarterly Journal of Engineering Geology and Hydrogeology, 1988, 21, No. 1, 59-68.

28. SIA A. H. I. and DIXON N. Distribution and variability of interface shear strength and derived parameters. Geotextiles and Geomembranes, 2007, 25, 139-154.

29. DUNCAN J. M. Factors of safety and reliability in geotechnical engineering. Journal of Geotechnical and Geoenvironmental Engineering, 2000, 126, No. 4, 307-316.

\section{What do you think?}

To comment on this paper, please email up to 500 words to the editor at journals@ice.org.uk

Proceedings journals rely entirely on contributions sent in by civil engineers and related professionals, academics and students. Papers should be 2000-5000 words long, with adequate illustrations and references. Please visit www.thomastelford.com/journals for author guidelines and further details. 